\title{
Should steroids be used for anaphylaxis after the COVID-19 vaccine?
}

\author{
Youngho Seo, Taekyu Ahn, Jinhui Paik, Soo Kang \\ Department of Emergency Medicine, Inha University College of Medicine, Incheon, Korea
}

\section{INTRODUCTION}

In late December 2019, cases of pneumonia of unknown etiology were reported in Wuhan, China. Severe acute respiratory syndrome coronavirus 2 caused an outbreak of coronavirus disease (COVID-19) in China, which then spread globally and was declared a pandemic in March 2020.' As of April 3, 2021, 104,736 cases of COVID-19 and 1,740 COVID-19-related deaths have been reported by the Korea Disease Control and Prevention Agency. ${ }^{2}$ For the prevention of COVID-19, the Ministry of Food and Drug Safety authorized the emergency use of the AstraZeneca COVID-19 vaccine (administered in two doses that are 1-3 months apart) on February 17, 2021 and the Pfizer-BioNTech COVID-19 vaccine (Comirnaty; administered in two doses that are 21 days apart) on March 28, 2021. As of April 3, 2021, 953,556 individuals have received the first-dose COVID-19 vaccination in South Korea, and 10,968 adverse events after COVID-19 vaccination have been reported to the Ministry of Food and Drug Safety. Among these reports, 108 were further reviewed as possible cases of severe allergic reactions, including anaphylaxis. ${ }^{2}$ Anaphylaxis is a life-threatening allergic reaction with an onset within minutes to hours that rarely occurs after vaccination. ${ }^{3}$ It is typically treated with adrenaline, and steroids and antihistamines are subsequently used as second-line anaphylaxis treatment. To the best of our knowledge, the effects of steroid use for treating anaphylaxis following COVID-19 vaccination have not yet been reported. We reviewed published reports on vaccine-associated anaphylaxis and the clinical effect of glucocorticoids on vaccine effectiveness and evaluated whether steroid use is necessary for patients who experience anaphylaxis after COVID-19 vaccination.

\section{MECHANISM OF POST-VACCINATION ANAPHYLAXIS}

Vaccine-associated anaphylaxis involves both immunoglobulin $\mathrm{E}(\mathrm{lgE})$-mediated reactions and non-lgE-mediated reactions. IgE-mediated reactions involve lgE/antigen cross-linking with the FceRI receptor on mast cells, which causes degranulation of mast cells and results in a type I hypersensitivity reaction. ${ }^{4}$ Non-lgE-mediated reactions involve mast cell activation by the complement system through the action of anaphylatoxins $\mathrm{C} 1 \mathrm{q}, \mathrm{C} 3 \mathrm{a}, \mathrm{C} 4, \mathrm{C} 5 \mathrm{a}$, and factor $\mathrm{B}^{5}$ and through a pathway involving the Mas-related $\mathrm{G}$ protein-coupled receptor X2. ${ }^{6}$ Allergic reactions directly induced by vaccines are rare, and most of them are caused by additives used to improve the absorption, stability, and solubility of the vaccine. ${ }^{6}$ An anaphylactic reaction occurs when the vaccine itself or an additive is sensitized as an antigen. Antigen-antibody complexes induce the release of large amounts of histamine and/or platelet-activating factors by mast cells, basophils,
eISSN: 2383-4625

Received: 21 May 2021

Revised: 23 August 2021

Accepted: 27 August 2021

Correspondence to: Jinhui Paik Department of Emergency Medicine, Inha University College of Medicine, 27 Inhang-ro, Jung-gu, Incheon 22332, Korea

E-mail: riven2ne@inha.ac.kr ORCID

https://orcid.org/0000-0001-9662-8457

Soo Kang Department of Emergency Medicine, Inha University College of Medicine, 27 Inhang-ro, Jung-gu, Incheon 22332,

Korea

E-mail:dr_peace@naver.com ORCID

https://orcid.org/0000-0003-0800-1350

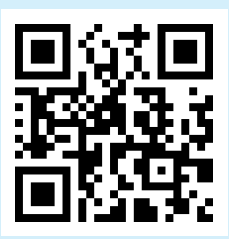

How to cite this article:

Seo Y, Ahn T, Paik J, Kang S. Should steroid be used for anaphylaxis after the COVID-19 vaccine? Clin Exp Emerg Med 2021;8(3):251-254. https://doi. org/10.15441/ceem.21.087

This is an Open Access article distributed under the terms of the Creative Commons Attribution Non-Commercial License (https:// creativecommons.org/licenses/by-nc/4.0/). 
and neutrophils. These mediators induce hypotension and vascular hyperpermeability, and subsequent anaphylaxis depends on the endothelial production of nitric oxide.? Immunologically mediated allergic reactions can occur as acute or delayed reactions. ${ }^{8}$ Most acute-onset reactions are type I hypersensitivity reactions mediated by preformed lgE antibodies against an antigenic vaccine component. $^{9}$

\section{GUIDELINES FOR ANAPHYLAXIS TREATMENT}

The World Allergy Organization has proposed guidelines for the assessment and management of anaphylaxis. If possible, exposure to the trigger should be halted as soon as a clinical diagnosis is established. The patient's circulation, airway, breathing, mental status, skin, and body weight (mass) should be assessed rapidly. Intramuscular injection of epinephrine is the first-line treatment; antihistamines and glucocorticoids can be used as second-line treatment. ${ }^{10,11}$ However, routine use of glucocorticoids might be harmful. ${ }^{10}$

\section{MECHANISM OF ACTION OF GLUCOCORTICOID THERAPY}

Steroids, including glucocorticoids, are commonly used to treat allergic and chronic inflammatory diseases, including asthma, dermatitis, rheumatoid arthritis, and even some cancers. ${ }^{12}$ Treatment with steroids leads to inhibition of the initial events of the inflammatory response to allergens. Vasodilation and increase in vascular permeability, which occur during acute inflammatory reactions, are inhibited, and migration of leukocytes is reduced. ${ }^{13}$ Since anaphylaxis is a type of acute allergic reaction, glucocorticoids can be used for its treatment.

\section{VACCINE FAILURE DUE TO STEROID USE}

Although glucocorticoids can be used to treat inflammatory reactions that occur as a part of anaphylaxis, their use for treating post-vaccination anaphylaxis might reduce the effectiveness of the COVID-19 vaccine. Studies have reported a correlation between vaccine effectiveness and steroid use; however, the specific relationship between COVID-19 vaccine effectiveness and steroid use has not been studied so far. Varicella has been reported to occur in patients on long-term steroid therapy who had been administered the varicella vaccine ${ }^{14}$; however, no case of influenza vaccine failure has been reported. ${ }^{15,16}$ Therefore, it is impossible to predict whether steroid use will reduce the effectiveness of the COVID-19 vaccine.

\section{CONTROVERSY OVER STEROID USE FOR TREATING ANAPHYLAXIS}

Although steroids are often used for treating anaphylaxis, there is no consensus among published guidelines regarding the use of glucocorticoids for the treatment of acute anaphylaxis. ${ }^{17-21}$ Recent retrospective multicenter studies conducted at emergency departments have reported that glucocorticoids are more commonly administered for treating anaphylaxis than adrenaline, which is the traditional treatment for anaphylaxis. ${ }^{22}$ One reason for this is that anaphylaxis is a biphasic reaction, which means that symptoms may recur after the initial anaphylaxis response resolves despite there being no further exposure to the antigen. ${ }^{23}$ Steroids can be effective for treating recurrent symptoms.

Although they are commonly used, there is no compelling evidence of the effectiveness of steroids for treating anaphylaxis. ${ }^{23-25}$ Several reviews of randomized or quasi-randomized controlled trials have failed to identify evidence of the effectiveness of steroids for treating anaphylaxis. ${ }^{22}$ In their recent meta-analysis, Shaker et al. ${ }^{26}$ advise against the use of glucocorticoids for treating anaphylaxis. However, in a recent systematic review, Liyanage et al. ${ }^{27}$ concluded that animal, laboratory, and human studies have found that using glucocorticoids for the emergency treatment of anaphylaxis has a beneficial effect and rational basis. Therefore, the use of glucocorticoids for treating anaphylaxis remains controversial, and emergency physicians are faced with a difficult decision.

\section{SUMMARY AND RECOMMENDATIONS FOR EMERGENCY PHYSICIANS}

To summarize, glucocorticoids help to control anaphylaxis by inhibiting vasodilation and increased vascular permeability, but the clinical effectiveness of steroids for treating anaphylaxis has not been verified. Furthermore, the fact that varicella developed after varicella vaccination in long-term steroid users suggests that steroid use affects vaccine effectiveness; however, influenza vaccine failure has not been reported in short-term steroid users. Since there has been no research on the impact of steroid use on COVID-19 vaccine effectiveness, treatments other than steroid therapy should be considered in patients with post-vaccination anaphylaxis. ${ }^{10}$ Even if symptoms subside after treatment, additional medical supervision is required..$^{11}$ Late-phase anaphylaxis occurs within 6 to 12 hours after the initial reaction..$^{10}$ Therefore, monitoring for more than 6 hours is necessary to detect symptoms of anaphylactic recurrence. ${ }^{28}$

A recent clinical review of allergic reactions after COVID-19 
vaccination reported that 21 of 1,893,360 patients who received the Pfizer-BioNTech COVID-19 vaccine experienced an anaphylactic response. Of them, 20 were discharged after treatment in an emergency room or hospital. ${ }^{29}$ Despite this, it is necessary to determine the optimal medical monitoring period in accordance with the World Allergy Organization anaphylaxis treatment guidelines. ${ }^{10}$ Emergency physicians should be aware of the need for medical monitoring, and we recommend that hospitalization for at least 12 hours, according to the World Allergy Organization anaphylaxis treatment guideline, should be considered for adequate observation.

\section{CONFLICT OF INTEREST}

No potential conflict of interest relevant to this article was reported.

\section{ACKNOWLEDGMENTS}

This work was supported by Inha University Hospital Grant.

\section{REFERENCES}

1. Zhou $P$, Yang $X L$, Wang $X G$, et al. A pneumonia outbreak associated with a new coronavirus of probable bat origin. $\mathrm{Na}-$ ture 2020;579:270-3.

2. Korea Disease Control and Prevention Agency. COVID-19 situation reports (April 3) [Internet]. Cheongju: Korea Disease Control and Prevention Agency; 2021 [cited 2021 May 21]. Available from: http://www.kdca.go.kr/board/board.es?mid = a2050 1000000\&tbid $=$ 0015\&list_no $=712923 \&$ tact $=$ view\# wrap.

3. CDC COVID-19 Response Team; Food and Drug Administration. Allergic reactions including anaphylaxis after receipt of the first dose of Moderna COVID-19 vaccine: United States, December 21, 2020-January 10, 2021. MMWR Morb Mortal Wkly Rep 2021;70:125-9.

4. Olivera $A$, Beaven MA, Metcalfe DD. Mast cells signal their importance in health and disease. J Allergy Clin Immunol 2018; 142:381-93.

5. Reber LL, Hernandez JD, Galli SJ. The pathophysiology of anaphylaxis. J Allergy Clin Immunol 2017;140:335-48.

6. Kounis NG, Koniari I, de Gregorio $C_{\text {, et al. Allergic reactions to }}$ current available COVID-19 vaccinations: pathophysiology, causality, and therapeutic considerations. Vaccines (Basel) 2021;9:221.

7. Nakamura T, Murata T. Regulation of vascular permeability in anaphylaxis. Br J Pharmacol 2018;175:2538-42.
8. McNeil MM, DeStefano F. Vaccine-associated hypersensitivity. J Allergy Clin Immunol 2018;141:463-72.

9. Wolbing F, Fischer J, Koberle M, Kaesler S, Biedermann T. About the role and underlying mechanisms of cofactors in anaphylaxis. Allergy 2013;68:1085-92.

10. Cardona V, Ansotegui IJ, Ebisawa M, et al. World Allergy Organization anaphylaxis guidance 2020. World Allergy Organ J 2020;13:100472.

11. Simons FE, Ardusso LR, Bilo MB, et al. World Allergy Organization anaphylaxis guidelines: summary. J Allergy Clin Immunol 2011;127:587-93.

12. Baschant $U$, Tuckermann J. The role of the glucocorticoid receptor in inflammation and immunity. J Steroid Biochem Mol Biol 2010;120:69-75.

13. Coutinho $A E$, Chapman KE. The anti-inflammatory and immunosuppressive effects of glucocorticoids, recent developments and mechanistic insights. Mol Cell Endocrinol 2011; 335:2-13.

14. Verstraeten $T$, Jumaan $A 0$, Mullooly $J P$, et al. A retrospective cohort study of the association of varicella vaccine failure with asthma, steroid use, age at vaccination, and measlesmumps-rubella vaccination. Pediatrics 2003;112:e98-103.

15. Hanania NA, Sockrider $M$, Castro $M$, et al. Immune response to influenza vaccination in children and adults with asthma: effect of corticosteroid therapy. J Allergy Clin Immunol 2004; 113:717-24.

16. Park $C L$, Frank AL, Sullivan $M$, Jindal $P$, Baxter BD. Influenza vaccination of children during acute asthma exacerbation and concurrent prednisone therapy. Pediatrics 1996;98(2 Pt 1):196-200.

17. Simons FE. Anaphylaxis: recent advances in assessment and treatment. J Allergy Clin Immunol 2009;124:625-36.

18. Muraro A, Worm M, Alviani $C$, et al. EAACl guideline: anaphylaxis (2021 update). Allergy 2021 Aug 3 [Epub]. https://doi. org/10.1111/all.15032.

19. Campbell RL, Li JT, Nicklas RA, Sadosty AT; Members of the Joint Task Force; Practice Parameter Workgroup. Emergency department diagnosis and treatment of anaphylaxis: a practice parameter. Ann Allergy Asthma Immunol 2014;113:599608.

20. Waserman S, Chad Z, Francoeur MJ, et al. Management of anaphylaxis in primary care: Canadian expert consensus recommendations. Allergy 2010;65:1082-92.

21. Burton $C$, Worth A. UK Resuscitation Council guidelines on emergency treatment of anaphylactic reactions: a primary care perspective. Prim Care Respir J 2008;17:60-1.

22. Choo KJ, Simons FE, Sheikh A. Glucocorticoids for the treat- 
ment of anaphylaxis. Evid Based Child Health 2013;8:127694.

23. CDC COVID-19 Response Team; Food and Drug Administration. Allergic reactions including anaphylaxis after receipt of the first dose of Pfizer-BioNTech COVID-19 vaccine: United States, December 14-23, 2020. MMWR Morb Mortal Wkly Rep 2021;70:46-51.

24. Sheikh A. Glucocorticosteroids for the treatment and prevention of anaphylaxis. Curr Opin Allergy Clin Immunol 2013;13: 263-7.

25. Simons FE. Pharmacologic treatment of anaphylaxis: can the evidence base be strengthened? Curr Opin Allergy Clin Immunol 2010;10:384-93.
26. Shaker MS, Wallace DV, Golden DB, et al. Anaphylaxis-a 2020 practice parameter update, systematic review, and Grading of Recommendations, Assessment, Development and Evaluation (GRADE) analysis. J Allergy Clin Immunol 2020;145:1082-123.

27. Liyanage CK, Galappatthy P, Seneviratne SL. Corticosteroids in management of anaphylaxis; a systematic review of evidence. Eur Ann Allergy Clin Immunol 2017;49:196-207.

28. Kim TH, Yoon SH, Hong H, Kang HR, Cho SH, Lee SY. Duration of observation for detecting a biphasic reaction in anaphylaxis: a meta-analysis. Int Arch Allergy Immunol 2019;179:31-6.

29. Shimabukuro T, Nair N. Allergic reactions including anaphylaxis after receipt of the first dose of Pfizer-BioNTech COVID-19 vaccine. JAMA 2021;325:780-1. 